DOI: $10.52950 / E S .2021 .10 .2 .009$

\title{
TOWARDS THE CONSTRIBUTION OF ECONOMICS TO THE DEVELOPMENT OF ITS SCIENTIFIC NEIGHBORS. THE CASE OF A LEGAL SCHOLARSHIP*
}

\section{DUSAN TRISKA}

\begin{abstract}
:
In Tríska (2017) have been suggested ways how legal scholarship (LS) may contribute to the development of economics - economic theory (ET). The objective of the present article is to corroborate a reverse know how transfer, i.e. from ET to LS. Its method is thus primarily derived from how micro-economics approaches the institution of a homo economicus.

The articles objective is to show under what conditions can this economic method be expanded and generalized so as to open ways for its application upon neighboring disciplines of societal studies. The outcome of this endeavor- for want of a better term - is presented under the label of a General Theory of Choice and Behavior (GTCB).

Moreover, it is argued that - under the umbrella of GTCB - the disciplines can establish their genuine scientific underpinning and hence also absorb a formalized analytical tool-kit. For concreteness, this conclusion is illustrated for legal scholarship, namely its concept a contract to be strictly taken in the economics sense of a collective choice.

On the highest level of generalization, the article should be understood as a response to the seminal Elinor Ostrom's call for an agreement amongst societal scholars upon universally acceptable analytical building blocks.
\end{abstract}

\section{Keywords:}

Science, choice, preferences, constraints, maximization, contract, collective choice

JEL Classification: A11, A23, C70

\section{Authors:}

DUSAN TRISKA, University of Economics and Business in Prague, Czech Republic, Email: dusan.triska@fsp.cz

\section{Citation:}

DUSAN TRISKA (2021). TOWARDS THE CONSTRIBUTION OF ECONOMICS TO THE DEVELOPMENT OF ITS SCIENTIFIC NEIGHBORS. The case of a legal scholarship*. International Journal of Economic Sciences, Vol. X(2), pp. 141-155., 10.52950/ES.2021.10.2.009

* The term "neighbor" is use here in the sense of Buchanan (1966). 


\section{INTRODUCTION}

\subsection{Paradigms of thought; their defenses and alternations}

With the aim to confront legal scholarship (LS) with science, the latter term will be used in its strictest sense, namely that of Aristotle's potentia and energeia, Karl Popper's falsifiability and Thomas Kuhn's paradigm of a scientific thought.

In particular, we will accept Kuhn's idea that a scientific "truth" is nothing more or less than an outcome a social choice, namely the choice of a particular community of scholars. ${ }^{1}$ Hence, only a well organized scientific community may bring forward and defend a paradigm of thought, namely force scholars:

- to respect the community's epistemological taboos,

- to apply only canonized analytical building blocks through which they may only present their findings to the community.

To illustrate, on the sacred soil of a nonrelativistic physics only notions such as time, mass, force, space, velocity, ... will be allowed. Similarly, theoretical economists have "decided to believe" that there exists a self-contained system called economy within which operate two and only two kinds of agents - producers (firms) and consumers (households).

The purpose of these limits to creativity is to defend the existing paradigm against irresistible temptations to endlessly search for a cause of every cause - so as to get finally lost in the chain of infinite recursions. Hence, a survival of a paradigm is in fact a miracle brought about by the community's improbable agreement upon a closure of their subject even though they all know that there is no such thing as a closed system. ${ }^{2}$

To summarize, science represents a pursuit of knowledge rather than the knowledge itself. Put differently, science can be characterized by Karl Popper's thesis that "theories are not generated by observations, but that observations are made in the light of theories". ${ }^{3}$

\subsection{General Theory of Choice and Behavior}

Accepting the above criteria of science we can hardly award this statute to LS. Rather we will include LS into disciplines such as engineering and medicine that for practical purposes utilize fragments of the scientific knowledge. In order to promote their discipline into science, as said, our proposal to legal scholars will be to accept their discipline as a branch of GTCB (General Theory of Choice and Behavior). Moreover, GTCB itself will be presented as a "mere" applications of the general Aristotelian concept of a potentia and energeia according to which a motion (including human behavior) must be understood-explained as a derivative of some innate pressure or potential energy. ${ }^{4}$

As a result, legal scholars will be advised to join physicists and economists in their

\footnotetext{
${ }^{1}$ Similarly, Knight (1982) argued that “... truth is whatever emerged from the free discussion of reasonable men who approached the dialogue without prejudice and as good sports" - see Buchanan (1982).

${ }^{2}$ A genuine brake-through of the paradigm of physics has been described in, e.g., Whitehead (1963). By far more modest is the economics paradigm's change in Stiglitz (2001).

${ }^{3}$ Here and there we have applied relatively comprehensive summery https://en.wikipedia.org/wiki/Sciece.

${ }^{4}$ Our own concept of "social energy" can be traced to Tříska and Zieleniec $(1980,1982)$.
} 
never-ending search for the nature and origins of the potential energy and hence also the driving force of the processes within "legal systems". Returning to GTCB, it will be our thesis that the societal energy's origins can be associated to

$$
\text { agents' tasks (obligations, duties, plans, objectives, goals, ...) }
$$

We will call these agents Designees with the aim to emphasize our thesis that that their tasks are imposed upon them by other agents called Designers. ${ }^{5}$

As a result the two social roles - a Designer and Designee - will constitute - on a given (focal) LAYER of the analysis its two universal building blocks.

\section{UNIVERSAL BUILDING BLOCKS AND SUB-BLOCKS OF A SOCIETAL ANALYSIS}

\subsection{Designer vs. Designee}

\subsubsection{Diversity of social contexts}

To elucidate the empirical meaning of the above building blocks the following examples may be of value:

Collective public Designer: $\quad$ The Parliament - as a Legislator - designs public tasks (obligations, duties) of Citizens thus converting them into Designees.

Contractual private Designer: Mary and John as a contract counter-parties jointly design each other as two counter-Designees bearing their respective private (contractual) counter-tasks.

Individual self-Designer: John designs his own private task - to be rather termed plan, objective, goal, given the particular social context.

Hypothetical Designer: $\quad$ The invisible hand of Adam Smith can be seen as a Designer of anonymous market participants, e.g., the firms (producers) with their tasks to maximize profits.

The intuition behind the examples should be that a Designer is a decision-maker by whose choice a Designee's behavior (or a task to behave) is designed. The examples also show that we will use the term "task" to represent a phenomenon for which depending on social contexts - are often used terms as obligation, duty, plan, objective, goal, ...6

\subsubsection{Example under study}

In Fig. 1 two-LAYER self-contained system is considered where a Legislator on LAYER 1 has decided that under given "war-time" conditions:

- Mary will be prescribed a task to deliver army uniforms,

- John will be prescribed a task to deliver machine guns.

\footnotetext{
${ }^{5}$ Apparently, the terms are strongly influence by the concept of mechanism design - cf., e.g., Hurwitz (2007).

${ }^{6}$ The term "task" has been selected due to the author's engagement in designing IT-systems.
} 


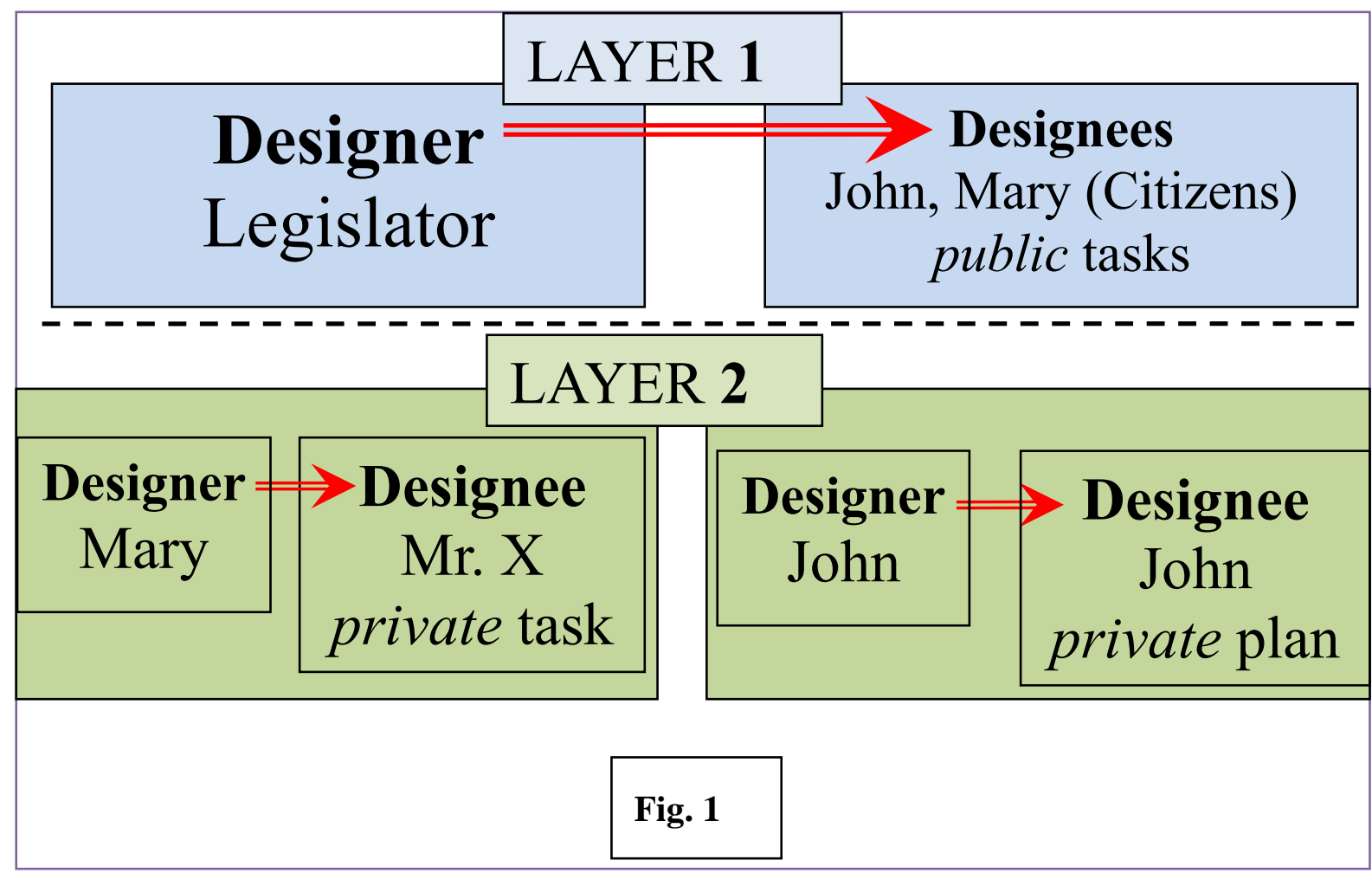

On LAYER 2 of the system, both Mary and John will be concerned by the uncertainty with which the war-time conditions may worsen and hence their respective public tasks prescribed. Under this innate pressure each of them will consider variant strategies how to fulfill the public task. To illustrate, let:

Mary decide for a strategy exemplified further by Mr. X's private task to deliver support to Mary's public task,

John decide for a self-relying strategy due to which he will design only his own task - his plan, objective, goal.

Summarizing, then, in order to find the best/optimal strategy how to cope with the public task, Mary as well as John will on LAYER 2 metamorphose into a Designer so as to design his or her respective Designees.

\subsection{Sub-blocks for a Designer}

\subsubsection{Designer's rationality}

From the methodological tool-kit of ET we will now recommend to legal scholars the vehicles referred to as

preferences and constraints

Moreover, on this LAYER of the analysis preferences and constraints will be accepted as two and only two analytical sub-blocks by which a Designer will be understoodexplained. In more detail we will characterize the sub-blocks through the following four axioms of rationality. A Designer, as any decision-maker indeed, will be taken as rational if he-she:

Axiom 1: understands the nature and origins of his-her "problem" - his-her innate pressure.

Axiom 2: can establish a SET of strategies about which he-she believes to be both relevant and feasible. The infeasibility of other relevant strategies then 
constitute constraints to his-her particular purpose.

Axiom 3: can compare any two strategies with respect to his-her tastes or distastes or, what comes to the same thing, his-her preferences.

Axiom 4: is able to select one and only one strategy as his best/optimal strategy how to relieve his-her innate pressure.

Controversies over how realistic or unrealistic are the Axioms can be, by and large, relaxed by their stubborn subjectivity. Our decision-maker will be rational irrespective of how "irrational" he-she may be seen by the rest of the Universe. To us, he-she will remain rational, even if he-she, e.g., believes that the Air Force One is available for the use of every Citizen every time.

Axiom 4 will be taken as our ultimate criterion of irrationality. A decision-maker will be classified as irrational if paralyzed by his-her indecisiveness, e.g., because he-she has selected two or more strategies that appear to him as "equally optimal". 7

\subsubsection{Utility maximization; philosophy vs. mathematics}

By accepting the above two sub-blocks we in fact accept from ET also their analytical ("mathematical") representation in the form of a utility maximization model. For concreteness and simplicity we will introduce the model for Mary operating as a Designer on LAYER 2 of Fig. 2.

Axiom 1 requires from Mary that she is aware of the fact that her innate pressure is generated by her public task to deliver army uniforms - under specific war-time conditions.

For the sake of Axiom 2, we will introduce notation

$$
\left\{s t r_{1}^{M}, s t r_{2}^{M}, \ldots, s t r_{m}^{M}\right\}
$$

representing a SET of $\boldsymbol{m}$ strategies about which only Mary believes to be feasible. As already explained, the SET constrains Mary's choice in the sense that there may exist highly relevant strategies that she may not select because they are, e.g., "beyond her budget".

As to Axiom 3, ET's tool-kit offers its utility function $U^{M}\left(s t r^{M}\right)$ by which Mary's preferences can be expressed. In particular, the (mathematical) inequality

$$
U^{M}\left(s t r_{k}^{M}\right)>U^{M}\left(s t r_{j}^{M}\right)
$$

states that Mary considers the $\boldsymbol{k}^{\text {th }}$ strategy $\operatorname{str}_{k}^{M}$ (e.g. the uniforms' import from USA) as better than the $j^{\text {th }}$ strategy $s t r_{j}^{M}$ (the import from China).

Finally, due to Axiom 4 Mary manages to select her best/optimal strategy - exemplified already by Mr. X, where, let us summarize:

- Mr. X (i.e. his task to provide support) must have belonged to the SET of feasible strategies Mr. X $\in\left\{s t r_{1}^{M}, s t r_{2}^{M}, \ldots, s t r_{m}^{M}\right\}$,-

- for Mr. X the function $U^{M}\left(s t r^{M}\right)$ reaches its maximum on the SET.

\footnotetext{
7 This case of irrationality is traditionally illustrated by Buridan's ass who will die from hunger between two identical piles of hay. Another kind of irrationality will occur to an agent who will find to every "best" strategy a still better one.
} 
Thanks to Mary's rationality we can now formally represent her choice of Mr. X by the following maximization problem: 8

$$
\begin{aligned}
& \max U^{M}\left(s t r^{M}\right) \\
& \text { s.t.: } s t r^{M} \in\left\{s t r_{1}^{M}, s t r_{2}^{M}, \ldots, s t r_{m}^{M}\right\}
\end{aligned}
$$

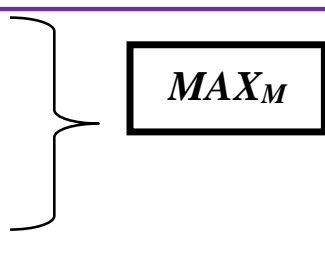

Our lesson in mathematics will then continue so that should $U^{M}(M r . X)$ be the maximum of $U^{M}\left(s t r^{M}\right)$ on the given SET, the partial derivatives of $U^{M}\left(s t r^{M}\right)$ must satisfy particular "first-order conditions" for the strategy denoted $M r . X$.

Hence, in order to solve $\boldsymbol{M A X}_{\boldsymbol{M}}$ - to find Mr. X - Mary has to calculate out the (mathematical) derivatives of $U^{M}\left(s t r^{M}\right)$. In this sense Mr. X is "derived" from Mary's utility function. Hence, the utility function $U^{M}\left(s t r^{M}\right)$ can be nicely interpreted as the embodiment of Mary's innate pressure. In sum, $\boldsymbol{M A X}_{\boldsymbol{M}}$ represents the Aristotelian concept of Mary's potential energy from which Mr. X's resultant "task to behave" is derived.

\subsubsection{Summary}

As explained, the upper and lower rows of $\boldsymbol{M A} \boldsymbol{X}_{\boldsymbol{M}}$ represent the two sub-blocks of Mary in her role of a Designer - her preferences and constraints, respectively. In Fig. 2 mutatis mutandis the maximization problems

\section{MAXLEG and MAXJ}

represent innate pressures of the other two Designers from Fig. 2 - the Legislator and John.

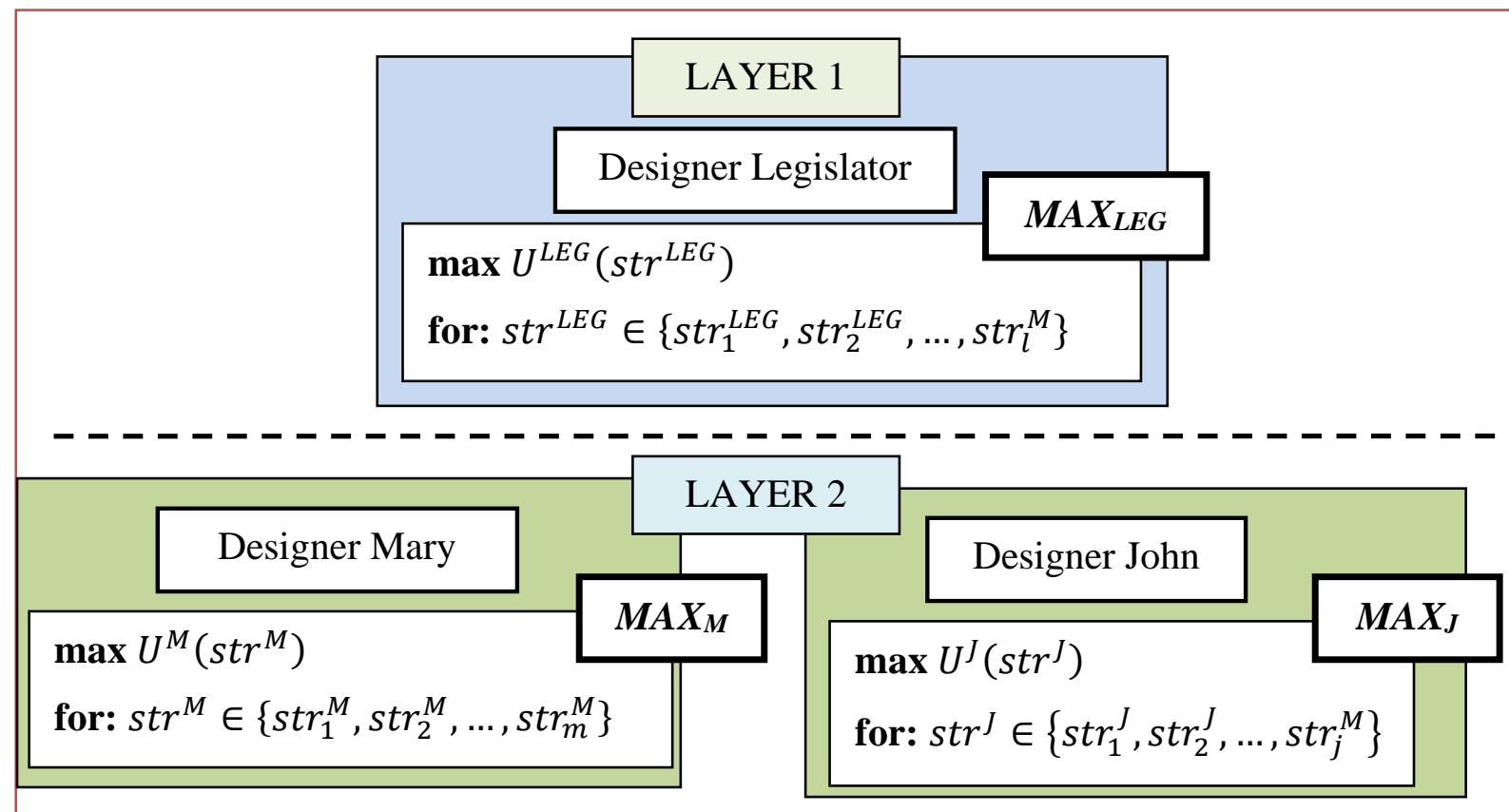

Fig. 2

8 A broader view on the very principle of maximization - in physics and social science - can be obtained from Samuelson (1970). 
In conclusion, let it be also noted that we have escaped the ill-fated problem of the infinite recursion only thanks to the closure of the system under study, primarily by our tabooization of questions about:

- Legislator's innate pressure and

- Mr. X's strategies how to relieve his innate pressure imposed upon him by the private task designed by Mary.

\subsection{Sub-blocks for a Designee}

It may be well to stress again that what a Designer designs is not a Designee's behavior but "only" a task to behave in a designed way. Moreover, the notion of a task bears - in itself - only little meaning unless it is supplemented by conditions, under which it may only be prescribed for fulfillment.

To illustrate, let us turn to Mary again, this time in her role of a Designee designed by a Legislator on LAYER 1 of Fig. 2. Her war-time task to deliver uniforms will become an entirely different "task" should the Designer associate it to some peace-time events, e.g., technological progress in Mary's firm. Not only that, the particular specification of Mary's delivery's parameters will generally depend on how exactly the particular conditions have been satisfied.

Put formally Mary - as a Designee - is in fact designed by one inseparable IF-THEN rule or a mapping

$$
\left[m:\langle\text { conditions }\rangle \rightarrow\left\langle\text { task's }^{\prime} \text { prescriptions }\right\rangle\right]
$$

Put differently, conditions and tasks constitute in fact one inseparable - universal, analytical - building block by which a Designee should be understood-explained.

Yet, for convenience of speech also we will sometimes resort to the inconsistency where the term "task" is used to represent a Designee as a whole. The, albeit weak, apology may refer to our ambition to keep in touch with the conventional terminology, namely the traditional disintegration of a legal norm into hypothesis (condition), disposition (task's prescription) and sanction. ${ }^{9}$ This way or another, to the extent that the condition is omitted, the respective design is incomplete. ${ }^{10}$

Finally, with the aim to bring forward a universal format of a Designee and his-her task we will also propose to always interpret a task as a delivery of something - be it an ordinary material good or an intangible asset as, e.g., sovereignty of the nation. To illustrate, a task to refrain from smoking should be translated into a task to deliver clean air. What is here in fact proposed is a deep re-interpetation of the classical terminology dare (to give), facere (to act), omittere (to forbear) a pati (withstand).

\section{EPISTEMIC VIRTUES}

\subsection{Towards the notion of an institution and social rule}

As said, our aim is to build methodological bridge not only between LS and ET but also towards IS (institutional scholarship). For that matter Fig. 3 summarizes the preceding discussion so as to expand it by a few concepts of IS as follows:

\footnotetext{
${ }^{9}$ In Tříska (2017) we show that a sanction should be rather taken as a entirely separate IF-THEN rule.

10 This is our first contribution to the phenomenon of incompleteness - cf. Hart (2016).
} 
preferences and constraints are interpreted as building sub-blocks by which social rules of choice are construed,

task and condition represent building sub-blocks by which social rules of behavior are construed.

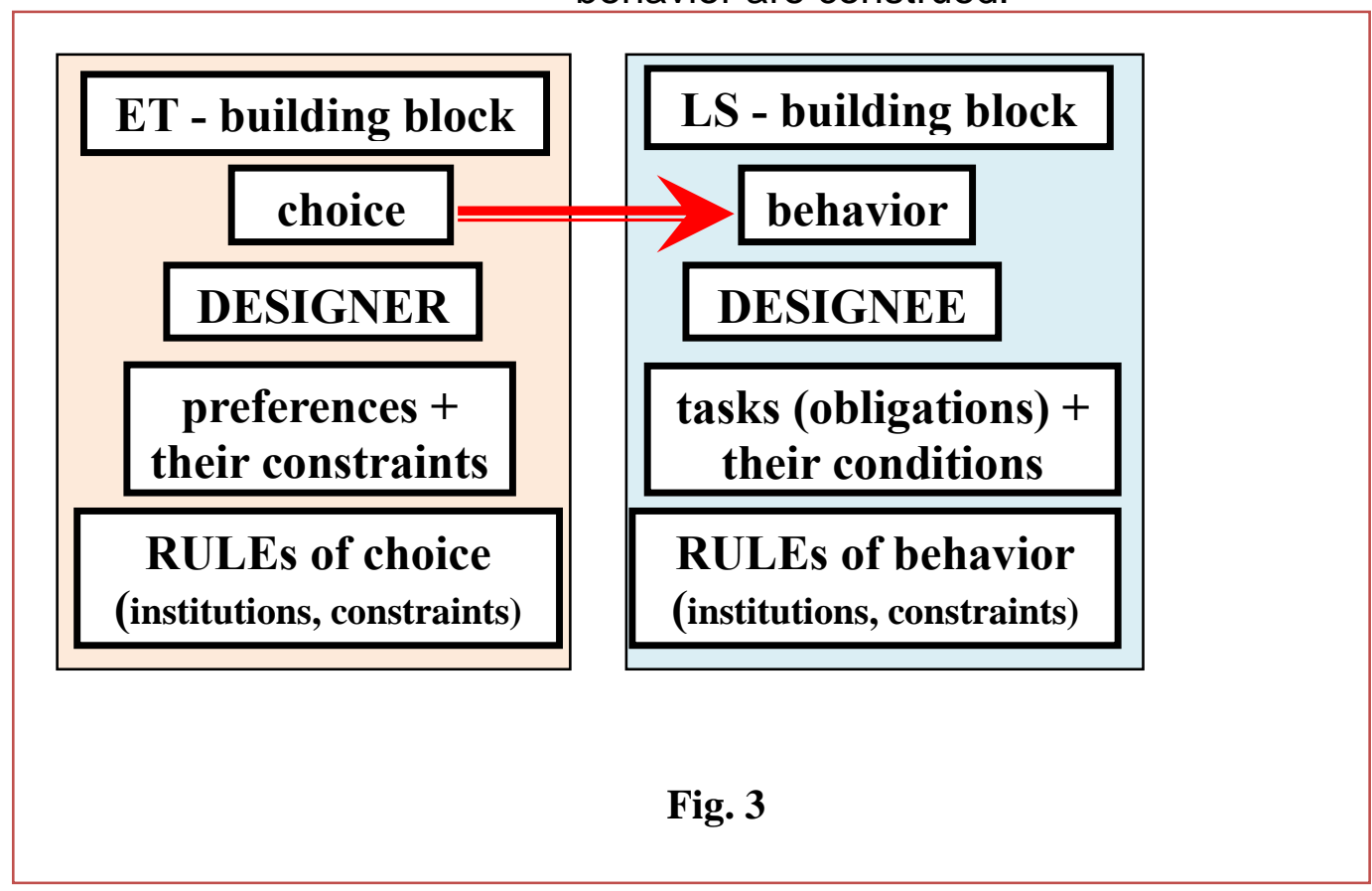

In Fig. 3 we in fact offer a somewhat deeper interpretation of the concept according to which an institution amounts to a set of social rules which are then taken as constraints to social choice or behavior. ${ }^{11}$

\subsection{Toward the notions of a social kinetics and dynamics}

A lawyer, unlike an economist, may easily accept that a task (obligation) develops passes through various stages of its development. Given that a task by itself bears almost no empirical meaning, we shall rather speak about a development of a Designee - from his-her "creation" through various stages of "maturity" to the inevitable "extinction".

For concreteness, we will return to Mr. X from LAYER 2 of Fig. 1 and his task to deliver support to Mary's fulfillment of her public task. By kinetics we will then understand a simple enumeration of Mr. X's development stages, e.g. those represented by the three transitions in Fig. $4 .^{12}$

\footnotetext{
11 Cf. North (1993).

${ }^{12}$ A by far more sophistical discussion of development stages can be found in Tríska (2009).
} 


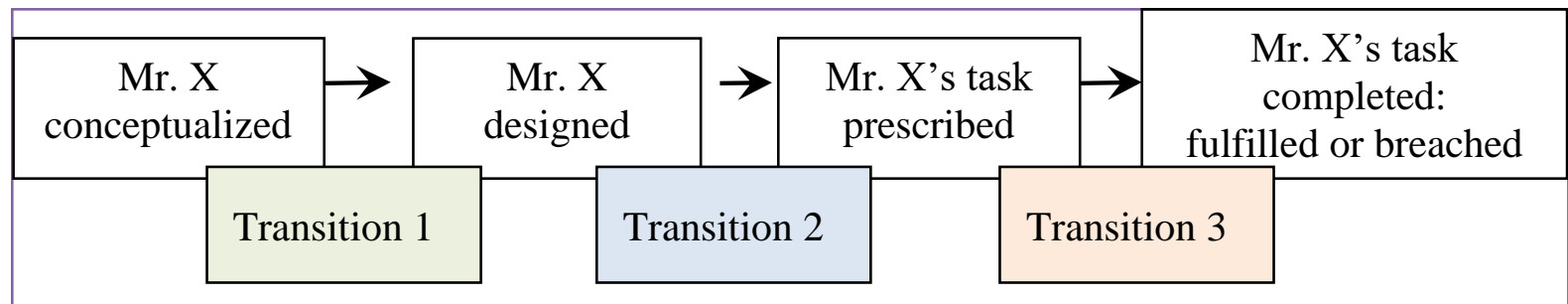

Fig. 4

In contrast, by dynamics we will understand the driving forces of the above transitions - their causes. To begin with, the driving force of Transition 1 has been already explained as a derivative of Mary's innate pressure and formally represented by the utility maximization model $\boldsymbol{M A X}_{\boldsymbol{M}}$.

As concerns Transition 2 the stage "prescribed" involves the fact that the task's conditions have been satisfied. Depending on how exactly they have been satisfied it is then possible to calculate out how exactly Mr. X will have to support Mary's public task.

In an ordinary language the looked-for driving force of Transition 2 - its dynamics - can be taken as an outcome of a negotiation between:

a Beneficiary who embodies the simple fact that a task is always designed in favor of somebody who is - put differently - awarded the exclusive "right" to claimdemand the task's prescription and fulfillment,

a Defendant whom we will here only briefly characterize as an agent who is entitled to raise objections against a fully justified claim of the Beneficiary.

Let, for simplicity, the role of a Defendant be performed by Mr. X himself, whereas - for dramatic effect - "a third person" named Sophia will be the Beneficiary of Mr. X's task.

Turning to the language of ET we will rather say that Mary - by designing Mr. X - has in fact established

$$
\text { a two-member organization [sx] }
$$

of which Sophia and Mr. X are the two members. Hence, Mr. X' task's prescription must be seen as an outcome of [sx]'s choice and therefore obtained - again - as a derivative of the organization's innate pressure - its preferences and constraints.

Therefore, to disclose the looked-for driving force of Transition 2 we should firstly address the philosophical puzzle concerning the very notion of an organization's innate pressures. We will leave this for later and - at this point - rather pin point the logistics and mechanics of this particular kind of a collective choice. We will characterize it as an election held on the floor of the particular organization. In the particular case of [sx] we should recall that it was Mary who - by designing Mr. X - determined the rules of this particular "game". Of them let us stress the following two:

- only Sophia and Mr. X have access to the floor and

- it is always Sophia who casts her vote as the first one.

\subsection{Towards the notion of a right}

\subsubsection{A right as a condition of a task}

Invoking Miss Sophia in her role of a Beneficiary, she was - so far in plain terms - 
established by her exclusive right to claim/demand prescription-fulfillment of Mr. X's task. Put equivalently, the task must not be prescribed if Sophia remains silent. Hence, the requirement that Sophia makes the claim is simply one of the conditions of Mr. X's task.

Other examples:

- a right of a detainee "to make one phone call" should be understood as a condition under which the police has to deliver access to the particular means of communication,

- a right to free speech essentially means that if, e.g., Mr. ZZ deliberately intrudes into this liberty he may be prescribed to deliver a particular amount of his time to a particular prison, ${ }^{13}$

- a right of Mrs. B to undisturbed Sunday afternoons in fact states that Mr. ZZ as anybody else, indeed - has a task to deliver to Mrs. B peace and quiet, IF it is Sunday afternoon.

Summarizing, then, the (lower-case) rights are in fact not genuine rights. They are conditions designed by a particular Designer, e.g., - as above - by Mary, crime-procedure Legislator, constitutional Legislator and a local authority.

\subsubsection{A natural RIGHT to be rational}

In contrast to Sophia's (lower-case) right/condition, an (upper-case) RIGHT will now stand for what one can - intuitively - see as Sophia's freedom to make a choice whether and how to demand Mr. X's task's prescription.

Invoking our Axiom 4 of rationality, Sophia's capacity to make this choice is the key characteristic of her being rational. Yet, the same (upper-case) RIGHT applies to any other agent. Simply anybody may decide to demand that Mr. X's task be prescribed and finally fulfilled. Also, e.g., Mr. ZZ with no (lower-case) right can decide to claim however useless may appear his "move" to the outside observers. Let us only repeat that by us Mr. ZZ will remain perfectly rational, insofar he believes that by the claim he will relieve his particular innate pressure whatever may be its nature and origin.

The puzzle associated to this general freedom of choice can be turned into the question who gave us this (upper-case) RIGHT. The following quote may illuminate the core of this clearly philosophical problem: "Depending on two theories of ethics, the mystical or the social, some man assert that right are a gift of God - others, that rights are a gift of society. But, in fact, the source of rights is man's nature."14

A simple application of the above Axiom 4 will tell us that what is in fact given to us is our capability of being rational. Consequently, and in full accordance with the above quote, there is no way how this kind of a gift could be provided by a society - and hence we must agree that only "man's nature" can be the source of human rationality.

Returning from the stratosphere of philosophical puzzles to the real-world problems, one of them could be how to interpret situation when Sophia remains silent. In the first place, Mary could have "deliberately" decided to remain silent because she does not want Mr. X's task to be prescribed. The other possibility is then that she got irrationally

\footnotetext{
13 Properties of this kind of rights are discussed in detail by, e.g., Okun (1974).

${ }^{14}$ Cf. Rand (1963).
} 
"stuck" by the endless Hamletish question "to claim or not-to claim". ${ }^{15}$

\subsubsection{A task to claim}

The above case when Sophia is "free to claim" should now be compared with the - as if - opposite setting where she will be - loosely said - "obliged" to claim or "obliged" not to claim. As explained, the particular form of Sophia's choice is a derivative of her innate pressure - whatever may be its nature and origins. Let then, its origin have the form of a particular form of Sophia's task. Put somewhat more precisely, assume that Mr. ZZ has decided to design conditions under which Sophia will have to demand Mr. X's task's prescription.

Apparently, by introducing Mr. ZZ we open up the so far discussed focal LAYER of the analysis and consequently, the ill-fated infinite recursion becomes our main danger. Firstly we should ask under what innate pressure Mr. ZZ decides to designs Sophia as a Designee and what is his relationship to Mary who designs Sophia as a Beneficiary of Mr. X's task. Still more frustrating will then be the question, who will be the Beneficiary of Sophia's task - leading to the legendary question who will be the Guardian of a Guardian. ${ }^{16}$

Returning, again, from the heights of philosophy to practical problems, one of them will consider confusions by wordings such as "Sophia has to claim should Mr. X's task be prescribed". One way is to take Sophia's claim only as a condition, the other is to read the wording as a "compulsory order of performances". ${ }^{17}$

\subsection{Toward the notions of a contract and individual preferences aggregation}

Let us now modify the above setting so that Mr. X will no longer be designed by a sole choice of Mary but by - intuitively said - a contract between Mr. X and Mary according to which:

Mr. X will become a Designee with a task to support Mary's fulfillment of her public task,

Mary will become a Designee with a task to pay for Mr. X's support.

Our first observation is that the two Designees have the same Designer - further referred to as $[\mathbf{X M}]$. By this notation we express that the Designer is in fact a twomember organization of two co-Designers - Mr. X and Mary. Given that [XM] creates (designs) Mr. X and Mary, the first philosophical puzzle is who creates the Creator called $[\mathbf{X M}]$.

To open the second puzzle of a philosophical nature, recall the Aristotelian methodological dictum according to which Mr. X and Mary must be seen - again - as derivatives of [XM]'s innate pressure. Our key question must then be whether there are such things as preferences and constraints of an organization. Or, how to understandexplain the two rows of the following utility maximization model.

\footnotetext{
15 This is our second contribution to the phenomenon of incompleteness - cf. Hart (2016)

16 Cf. Hurwitz (2007).

17 This is our third contribution to the phenomenon of incompleteness - cf. Hart (2016)
} 


$$
\begin{aligned}
& \max U^{X M}\left(s t r^{X M}\right) \\
& \text { for: } s t r^{X M} \in\left\{s t r_{1}^{X M}, s t r_{2}^{X M}, \ldots, s t r_{x m}^{X M}\right\}
\end{aligned}
$$

Still more importantly, a question must be raised whether and how $\boldsymbol{M} \boldsymbol{A} \boldsymbol{X}_{\boldsymbol{X} \boldsymbol{M}}$ relates to the "individual" preferences and constraints of Mr. X and Mary, the only two members of $[\mathbf{X M}]$. In short: if the two members are rational (capable of making a unique choice), will also their organization $[\mathbf{X M}]$ be rational? ${ }^{18}$

One solution to the mysterious philosophical puzzles can be drawn from what ET has called a integrability problem. ${ }^{19}$ Its underlying idea is the following: If Designees are (mathematical) derivatives of their Designer, the Designer must be the (mathematical) integral of his-her Designees. Put differently, the building blocks of a Designer are construed as the integral of his-her Designees' building blocks.

Put concretely and in more detail, preferences and constraints of [XM] will be obtained by integrating Mr. X's and Mary's s conditions and tasks. The non-trivial consequence of this concept is that it contradicts the usual idea of aggregation of individual preferences. In sum, if the particular form of $\boldsymbol{M A X} \boldsymbol{X}_{\boldsymbol{X}}$ is the integral of conditions and tasks there is now way how it could embody aggregation of Mr. X's and Mary's preferences. ${ }^{20}$ As showed by Cermakova (2021) formulas of individual behavior will be translated in aggregate responses in the economy across sectors. Kaderabkova (2021) proves a significant impact of such aggregate responses on economic cycle at macro and mezzo levels. For example, particular sensitivity to shocks in individuals' expectations is shown in the construction sector (Hromada, 2021) and in financial sector (Klieber, 2021).

However speculative or highly formal can appear the epistemic virtue of our analysis, it can be supported, still only intuitively, as follows:

- Given that John and Mary from Fig. 1 are designed by their public tasks to deliver army uniforms and guns, we may relatively safely conclude that the integral of these "militaristic" designs can obtain the form of the Legislator's super-public task to deliver "sovereignty" to the respective nation.

- A consistent "integration" of tasks designed by the courts' verdicts inevitably leads to the legendary question. "What do judges maximize?". ${ }^{21}$

- It may be also illustrative to recall the biblical appeal: "By their fruits you will know them. Do you gather grapes from thorns, or figs from thistles?"22

\section{SUMMARY AND CONCLUSIONS}

The research has revealed that there exist accessible ways how to respond to Elinor Ostrom's call for universal analytical building blocks in social sciences. In particular, we

\footnotetext{
18 This kind of questions brings us to the Austrian school of thought, e.g. Mises (2010).

${ }^{19}$ Varian (1992, pp. 125 - 127).

${ }^{20}$ Cf. Arrow (1963).

21 Posner (1993).

22 Matthew 7:16
} 
have proposed a set of blocks by which can be construed a methodological bridge between micro-economics and legal scholarship - for the benefit of both.

The proposed methodological umbrella has been termed General Theory of Choice and Behavior (GTCB). Already this term asserts that the notion of a choice (decisionmaking") should be strictly differentiated from that of a behavior. For that matter, the choice's outcome is consecutively interpreted as a task, or - depending on a particular social setting - as an obligation, duty, plan, objective, or goal etc. Naturally then, an observed behavior may or may not be consistent with the outcome of the respective choice. Of interest to lawyers should thus be that economics is able to formalize this disparity by its models of the inter-temporal and-or uncertainty choice.

The normative virtue of the present article can thus be summarized by the seminal question "what should lawyers do?". ${ }^{23}$ Depending on their answer, legal scholars should:

- follow the example of economists and begin with the question "what is science?" and draw a clear line between themselves and "ordinary experts" practicing law - very much in the sense that economists "distanced themselves" from professional managers, accountants, tax advisor etc.,

- mobilize efforts so as to produce the text-book that could be of use irrespective of the particular jurisdiction so as to convey knowledge hidden - as a rule - under the jargon of legal documents,

- open their faculties to mathematics so that their profession would no longer rely solely on metaphoric description and understanding of legal phenomena. It is our thesis that only a formalized language can provide precision to terms such as retro-activity, repudiation, revocation, statute of limitation, excuse of a condition, waiver, estoppel, voidability, lack of action, forbearance, omission, plaintiff's contribution, compensatory damage, gap filler, partial fulfillment and breach, wrongful resolution, exclusion and exemption to exclusion. ${ }^{24}$

\section{ACKNOWLEDGEMENTS}

This research was founded by grant number IP 500040.

\section{REFERENCES}

ARROW, K.J. (1963): Social Choice and Individual Values, 2nd edition, Cowles Foundation Monographs Series, 1963. ISBN 978-0-30001364-1.

BUCHANAN, J. M. (1964): What Should Economists Do? Southern Economic Journal. Vol. 30, No. 3 (Jan., 1964), pp. 213-222

Buchanan, J. M. (1966). Economics and Its Scientific Neighbors. In Buchanan: What Should Economists Do? (pp. 115-142). Indianapolis: Liberty Fund.

BUCHANAN, J. M. (1982): Preface to Knight (1982).

\footnotetext{
${ }^{23}$ Cf. Buchanan (1964) or Shelling (1999). For a dose of respect to the complexity of the real-world cf. Hayek (1980, 1991 ) or, in particular Knight (1982) with the preface by Buchanan (1982) and interpretation in Burgin (2009).

${ }^{24}$ Ambiguousness of the terms is broadly discussed by, e.g., White and Summers (2010).
} 
BURGIN, A. (2009): The radical conservatism of Frank H. Knight, Modern Intellectual History, Volume 6, Issue 3 (2009), pp. 513-538, Cambridge University Press 2009, https://doi.org/10.1017/S1479244309990163.

CERMAKOVA, K.; BEJCEK, M.; VORLICEK, J.; MITWALLYOVA, H. Neglected Theories of Business Cycle-Alternative Ways of Explaining Economic Fluctuations. Data 2021, 6, 109. https://doi.org/10.3390/data6110109

GRAVELLE, H., REES, R. (2004). Microeconomics (3rd Edition). Pearson Education Canada. ISBN 9780-58240487-8.

HART, O. (2016). Incomplete Contracts and Control. Nobel prize lecture, December 8, 2016. Available at https://www.nobelprize.org/nobel prizes/economic-sciences/laureates/2016/hart-lectureslides.pdf .

HAYEK, F.A. (1980). Counter Revolution of Science. Liberty Fund. ISBN 978-0913966679.

HAYEK, F. A. (1991): The Fatal Conceit (Bartley, W. W. ed.): The Errors of Socialism (The Collected Works of F. A. Hayek), University of Chicago Press; 1 edition (August 28, 1991), ISBN-10: 0226320669" The curious task of economics is to demonstrate to men how little they really know about what they imagine they can design."

HROMADA, E., KRULICKY, T. Investing in Real Estate in the Czech Republic and Analyzing the Dependence of Profitability and Technical and Socio-Economic Factors. Sustainability. 2021; 13(18):10273. https://doi.org/10.3390/su131810273

HURWICZ, L. (2007). But who will guard the guardians? Nobel Memorial Lecture, December 8, 2007. Available at https:/www.nobelprize.org/nobel prizes/economicsciences/laureates/2007/hurwicz lecture.pdf

KADERABKOVA, B., JASOVA, E., HOLMAN, R. (2020). Analysis of substitution changes in the Phillips curve in V4 countries over the course of economic cycles. International Journal of Economic Sciences, Vol. IX(2), pp. 39-54. , DOI: 10.52950/ES.2020.9.2.003

KLIBER, P., RUTKOWSKA-ZIARKO, A. (2021). Portfolio choice with a fundamental criterion - an algorithm and practical applicationon - a computation methods and empirical analysis. International Journal of Economic Sciences, Vol. X(1), pp. 39-52. , DOI: 10.52950/ES.2021.10.1.003

KNIGHT, F.H. (1982): Freedom and Reform, Essays in Economics and Social Philosophy; Foreword by James M. Buchanan. Liberty Fund ISBN. 978-0-86597-004-5

Matthew 7:16: The sixteenth verse of the seventh chapter of the Gospel of Matthew in the New Testament

MISES, L. (2010): Human Action: A Treatise on Economics, Liberty Fund Inc.; SLP edition (February 16, 2010). ISBN-13: 978-0865976313

NORTH, D., C. (1993): Economic Performance through Time, Lecture to the memory of Alfred Nobel, December 9, 1993 https://www.nobelprize.org/prizes/economic-sciences/1993/north/lecture/

OKUN, A.M. (1974): Equality and Efficiency; The big tradeoff. The Brooking Institution ISBN 081576475 8.

OSTROM, E. (2006): Understanding Institutional Diversity, Princeton University Press, 2006, ISBN 9780691122380

OSTROM, E. (2009): Beyond Markets and States: Polycentric Governance of Complex Economic Systems, Prize Lecture, December 2009, https://www.nobelprize.org/uploads/2018/06/ostrom lecture.pdf 
POSNER, R. A. (1993). What Do Judges and Justices Maximize? (The Same Thing Everybody Else Does). Supreme Court Economic Review 3 (1993), str. 1-41. Available at https://chicagounbound.uchicago.edu/cgi/viewcontent.cgi?article $=1616 \&$ context=law and econo mics.

RAND, A (1966): The Objectivist Newsletter, Inc., from Capitalisms: The Unknown Idea. New American Library. ISBN 978-0-451-14795-0

SAMUELSON, P.A.: Maximum Principles in Analytical Economics, Nobel Memorial Lecture, December 11, 1970 - available at https://www.nobelprize.org/uploads/2018/06/samuelson-lecture.pdf

SHELLING, T.C. (1999). What Do Economists Know? In: What Do Economists Contribute?, Klein, D.B. (red.), New York University Press, 1995ISBN 0-81474723-X.

STIGLITZ, J.E (2001). Information and the Change in the Paradigm in Economics. Nobel prize lecture, December $\quad 8,2001 . \quad$ Available at https://pdfs.semanticscholar.org/c31f/8ce662dc8b1a9e9e60652850e6f8906d15f9.pdf .

TŘíSKA, D. (2005). K některým možnostem optimalizace smlouvy a závazkových vztahů. (Towards Optimization of Contracts and Obligation Relationships), Oeconomica (2005), ISBN 80-245-09164 ..

TŘíSKA, D. (2009). Ekonomická analýza smluv, systemů a procesů. (Economic Analysis of Contracts, Systems and Processes), Oeconomica (2009), ISBN 9788024515755.

TŘíSKA, D. (2017). Social Choice and Behavior; the nature of their design and management. Praha: Walters Kluwer (2017), ISBN 978-8-07552921-3. Available at http://www.fsp.cz/social-choice-andbehavior/.

TŘíSKA, D., ZIELENIEC, J. (1980): Energy of Social Dynamics - unpublished monograph, Prague 1980.

TŘíSKA, D., ZIELENIEC, J. (1982): Potenciál lidské aktivity (Potential of Human Activity), Ekonomickomatematický obzor, 18 (1982), č. 1, Praha 1982.

VARIAN, H. R. (1992). Microeconomic Analysis (Third Edition). W. W. Norton \& Company, ISBN 978-039395735-8.

VARIAN, H. R. (2009). Intermediate Microeconomics: A Modern Approach (Eighth Edition). W. W. Norton \& Company, ISBN 978-0-39393424-3.

WHITE, J. J., SUMMERS, R. S. (2010): White and Summers' Uniform Commercial Code, Edition 6, (Hornbook Series) West Academic Publishing, 2010, ISBN-13: 978-1628103748.

WHITEHEAD, A.N. (1967): Science and the Modern World, Simon and Schuster, 1967, ISBN 9780684836393. 